Rapport - Société canadienne d'histoire de l'Église catholique

\title{
Rapport du Secrétaire adjoint de la section française
}

\section{Raymond Massé}

Volume 30, 1963

URI : https://id.erudit.org/iderudit/1007352ar

DOI : https://doi.org/10.7202/1007352ar

Aller au sommaire du numéro

Éditeur(s)

La Société canadienne d'histoire de l'Église catholique

ISSN

0318-6148 (imprimé)

1927-7075 (numérique)

Découvrir la revue

Citer ce document

Massé, R. (1963). Rapport du Secrétaire adjoint de la section française. Rapport -

Société canadienne d'histoire de l'Église catholique, 30, 9-10.

https://doi.org/10.7202/1007352ar

Tous droits réservés @ La Société canadienne d'histoire de l'Église catholique, 1964
Ce document est protégé par la loi sur le droit d'auteur. L'utilisation des services d'Érudit (y compris la reproduction) est assujettie à sa politique d'utilisation que vous pouvez consulter en ligne.

https://apropos.erudit.org/fr/usagers/politique-dutilisation/ 


\section{Rapport du Secrétaire adjoint de la section française}

La Société Canadienne d'Histoire d'Eglise Catholique tient son trentième congrès annuel à l'Université Laval de Québec, les vendredi, samedi et dimanche, 7, 8 et 9 juin 1963.

Le dimanche 9 juin, à dix heures de l'avant-midi, a lieu la réunion du Conseil d'administration de la Section française. La réunion est présidée par M. Albert Saint-Jean, C.0. St-S., président de la Section.

Les membres suivants sont présents : M. Albert Saint-Jean, Rév. Père Adrien Pouliot, s.j., Rév. Père Léon Pouliot, s.j., Rév. Père Gaston Carrière, o.m.i., Rév. Père Lorenzo Cadieux, s.j., Rév. Sœur Madeleine-Durand, f.c.s.p., Mme Reine Malouin, M. Conrad Charlebois, C. de l'O. St-G.G. et M. Raymond Massé.

Le secrétaire lit le rapport de l'assemblée tenue lors du congrès de juin 1962; ce rapport est adopté à l'unanimité.

Le trésorier présente son rapport financier qui est aussi adopté à l'unanimité. Les directeurs décident que le rapport financier ne sera plus publié dans le « Rapport annuel ".

Le Rév. Père Gaston Carrière, o.m.i., propose, secondé à l'unanimité, que la cotisation soit portée de trois à cinq dollars et qu'un membre qui ne paie pas sa cotisation durant trois années consécutives, ne soit plus considéré comme tel et ne reçoive plus le "Rapport annuel ".

Les officiers décident de ne pas tenir le prochain congrès conjointement avec la Section anglaise et dans le cadre du Congrès des Sociétés savantes. La raison qui motive cette décision est principalement que le prochain Congrès des Sociétés savantes aura lieu à Charlottetown. Il sera très difficiles à la Section française d'intéresser les gens de cette ville à leurs assises. Les directeurs sont aussi d'avis que c'est lors des congrès que l'on peut recruter le plus de nouveaux membres et que le fait d'avoir tenu les congrès dans les grands centres seulement, depuis quelques années, a grandement nui au recrutement.

Il est décidé que le congrès de 1964 aura lieu dans une ville du diocèse de Saint-Jérôme, si l'évêque y consent.

La Section française se fera représenter par au moins deux membres au congrès de la Section anglaise. Il est bien entendu que cette division des assises annuelles n'est pas permanente et que le congrès des deux sections pourraient de nouveau être tenus ensemble si les circonstances deviennent favorables. Il faudra former un comité fran- 
çais local à Charlottetown en vue d'inviter les Canadiens français de l'endroit et des environs à venir prendre part à ce congrès de la Section anglaise.

Les résultats des élections au Conseil d'administration pour le terme 1963-1964, sont les suivants : président : $\mathrm{M}^{\mathrm{gr}}$ Victor Tremblay, P.D,. Chicoutimi, P.Q.; vice-président : M. le Juge Léo Landreville, Toronto, Ont; secrétaire : M. Conrad Charlebois, C. de l'O. St-G.G., Hull, P.Q.; secrétaire adjoint: M. Raymond Massé, Hull, P.Q.; trésorier:

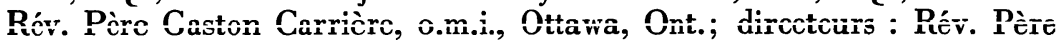
Adrien Pouliot, s.j., Québec, P.Q.; Rév. Sœur Madeleine-Durand, f.c.s.p., Montréal, P.Q.; Mme Reine Malouin, Québec, P.Q.; Rév. Père Lorenzo Cadieux, s.j., Sudbury, Ontario; Rév. Père Paul-Emile Breton, o.m.i., Edmonton, Alta; $\mathrm{M}^{\mathrm{gr}}$ Maurice O'Bready, C.S., Sherbrooke, P.Q.; M. l'abbé René Viau, Sainte-Thérèse-de-Blainville, P.Q.; M. l'abbé Michel Le Moignan, Gaspé, P.Q.

Immédiatement après a lieu la réunion conjointe d'administration des Sections française et anglaise. M. Albert Saint-Jean, C. de l'O. St-S., de Montréal, est élu président-général de la Société pour le prochain terme.

Les officiers de la Section anglaise sont mis au courant de la décision de la Section française à propos du prochain congrès. Ils acceptent cette décision avec regret et invitent tous les membres qui le pourront à assister à leur congrès. Ils expriment en plus le désir que deux conférenciers français de la Section française soient à leur programme.

L'assemblée est alors levée.

Le secrétaire adjoint

Raymond MAssÉ 